\title{
ERRATUM
}

\section{Concomitant leptospirosis-hantavirus co-infection in acute patients hospitalized in Sri Lanka: implications for a potentially worldwide underestimated problem - ERRATUM}

\author{
N. P. SUNIL-CHANDRA, J. CLEMENT, P. MAES, H. J. DE SILVA, \\ M. VAN ESBROECK AND M. VAN RANST
}

doi:10.1017/S0950268814003707, Published by Cambridge University Press, 13 January 2015

We regret to announce that there was a serious error in the last full paragraph on page 8 of the above mentioned paper [1] The incorrect sentence

That a double (separate or even concomitant) leptospirosis- hantavirus infection is a rarity in Sri Lanka is furthermore confirmed again in the retrospective study, giving $6 / 23$ or $26.0 \%$ incidence.

Should have read

That a double (separate or even concomitant) leptospirosis-hantavirus infection is all but a rarity in Sri Lanka is furthermore confirmed again in the retrospective study, giving $6 / 23$ or $26.0 \%$ incidence.

Also, on two occasions leptospirosis is given as leptosirosis.

The publishers apologise for these errors.

\section{REFERENCE}

1. Sunil-Chandra NP, Clement J, Maes P, De Silva HJ, Van Esbroeck M, Van Ranst M Concomitant leptospirosis-hantavirus co-infection in acute patients hospitalized in Sri Lanka: implications for a potentially worldwide underestimated problem. Epidemiology and Infection, doi:10.1017/S0950268814003707. Published online 13 January 2015. 